\title{
Храмовая архитектура Беларуси 1990-х - 2010-х годов: традиции и новые подходы
}

\author{
И.И.Балуненко, Центр исследований белорусской культуры, языка и литературы, Минск, \\ Беларусь \\ Т.В.Габрусь, Центр исследований белорусской культуры, языка и литературы, Минск, \\ Беларусь
}

В статье рассмотрены общие тенденции развития сакральной архитектуры Беларуси 1990-х - 2010-х годов и определены особенности католического, протестантского и православного зодчества. Общей чертой всех конфессиональных направлений храмовой архитектуры современной Беларуси является поиск баланса между экспериментами в формообразовании и обращением к традиции, подразумевающей историзм и соединение традиционных и новаторских элементов в стилевых рамках постмодернизма. В православной архитектуре эти тенденции проявляются в конфликте устремлений к русской и белорусской храмостроительной традиции, постмодернистском переосмыслении собирательного образа крестово-купольного храма. Историческая архитектура католицизма переосмыслена в русле эклектики XIX век, авангардное направление объединяет стилистику постмодернизма, деконструктивизма и неомодернизма. Облик домов молитвы ориентируется на протестантскую архитектуру США последней трети XX века; в исторических стилизациях используются приёмы православного и католического белорусского зодчества. В современной сакральной архитектуре сохраняется исторически присущая Беларуси многовекторность, которая подразумевает интерпретацию культурных и религиозных влияний Востока и Запада.

Ключевые слова: сакральная архитектура, православная архитектура, архитектура католицизма, протестантская архитектура, современная архитектура, новейшая архитектура, постмодернизм

\section{Church Architecture of Belarus in the 1990's - 2010's: Traditions and New Approaches}

I.I.Balunenko, Center for Research of Belarusian Culture, Language and Literature, Minsk, Belarus

T.V.Gabrus, Center for Research of Belarusian Culture, Language and Literature, Minsk, Belarus

The article examines the general trends in the development of Belarusian sacred architecture in the 1990s - 2010s and the unique features of local Catholic, Protestant, and Orthodox architecture. A common feature of Christian denominations in modern Belarus is the search for balance between experiments in design and preservation of traditional features that implies historicism and a combination of traditional and innovative elements within the stylistic framework of postmodernism.
In Orthodox architecture, these tendencies manifest in the conflict between the Russian and Belarusian church-building tradition revival; postmodernism manifests in the creative interpretation of the cross-in-square church. The historic architecture of Catholicism is revisioned through the lens of 19th-century eclecticism, the avant-garde trend combines stylistic conventions of postmodernism, deconstructivism, and neo-modernism. The look of Protestant houses of prayer is influenced by the Protestant architecture of the United States of the last third of the 20th century; historical stylizations employ the methods of Orthodox and Catholic architecture. The historically inherent multi-vector nature of Belarus is preserved in modern sacred architecture that interprets Western and Eastern cultural and religious influences.

Keywords: sacred architecture, Orthodox Christian architecture, Catholic architecture, Protestant architecture, modern architecture, contemporary architecture, postmodernism.

Сакральная архитектура Беларуси с 1990-х годов развивается в условиях возрождения интереса к религии: отмена советских ограничений свободы вероисповедания привела к росту количества прихожан Русской православной церкви, Римско-католической церкви и различных направлений протестантизма на рубеже 1980-х - 1990-х годов. В 1990-х годах начинает формироваться новая национальная культура, в которой проявляется многовековая история сосуществования религий на территории Беларуси, получившая естественное выражение в стилевых направлениях храмового зодчества.

Исторические предпосылки развития сакральной архитектуры Беларуси в 1990-е - 2010-е годы. В современном сакральном зодчестве Беларуси сталкиваются традиции белорусского, русского и западноевропейского искусства. Территория современной Беларуси исторически находилась на границе соприкосновения культур восточной и западной Европы, поэтому в сакральном зодчестве можно проследить соединение разновекторных художественных традиций (раннехристианских, византийских, древнерусских, западно-и центральноевропейских) и следы культурного обмена между различными христианскими конфессиями (православием, католицизмом, протестантизмом и греко-католицизмом). В Полоцкой и Гродненской школах зодчества, архитектуре Великого княжества Литовского, Речи Посполитой и Западной Беларуси 
в составе Польской Республики отразился выразительный язык романики, готики, ренессанса, барокко, классицизма, эклектики, модерна, движения национал-романтизма [1, с. 50]. В XIX веке территория современной Беларуси входила в состав Российской империи. С 1860-х годов в Северо-Западном крае велось активное строительство православных храмов в стилях, воплощавших собирательный образ древнерусского зодчества («русско-византийский», «русский» и «неорусский»), сносились либо перестраивались в «русском стиле» памятники архитектуры готики, ренессанса и барокко. Политика уничтожения белорусской храмовой архитектуры была продолжена в рамках антиклерикальной программы СССР.

Тенденции современной православной архитектуры Беларуси во многом обусловлены последствиями культурной политики Российской империи в XIX веке и ограничением свободы вероисповедания в СССР. На современном этапе новаторские архитектурные эксперименты уступают идее «возрождения» храмостроительных традиций, которая подразумевает два вектора развития: 1) следование образцам древнерусской архитектуры, «русского», «русско-византийского стилей» XIX

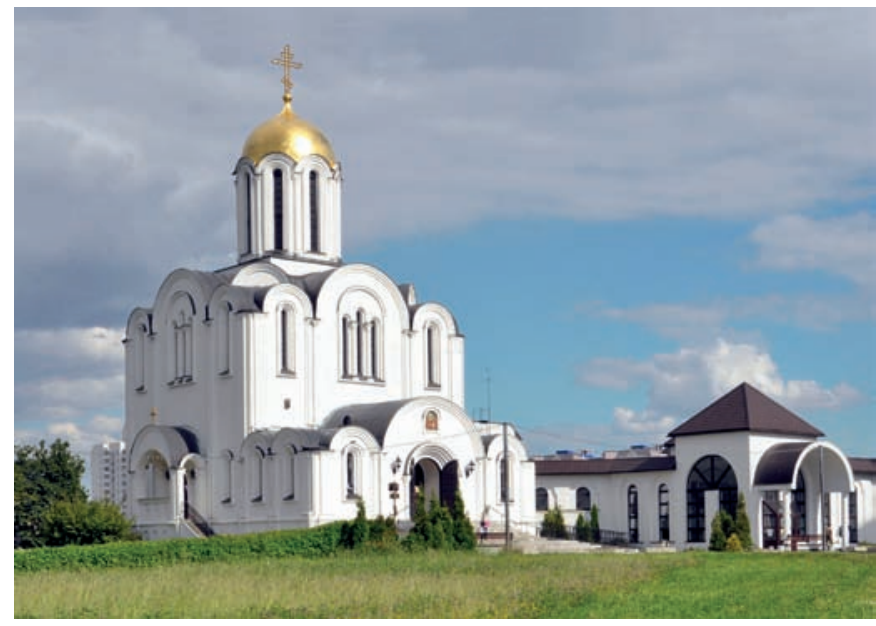

Рис. 1. Храм св. Евфросинии Полоцкой. Минск. Архитектор Н. Дятко. 1996 год. Фото И.И. Балуненко

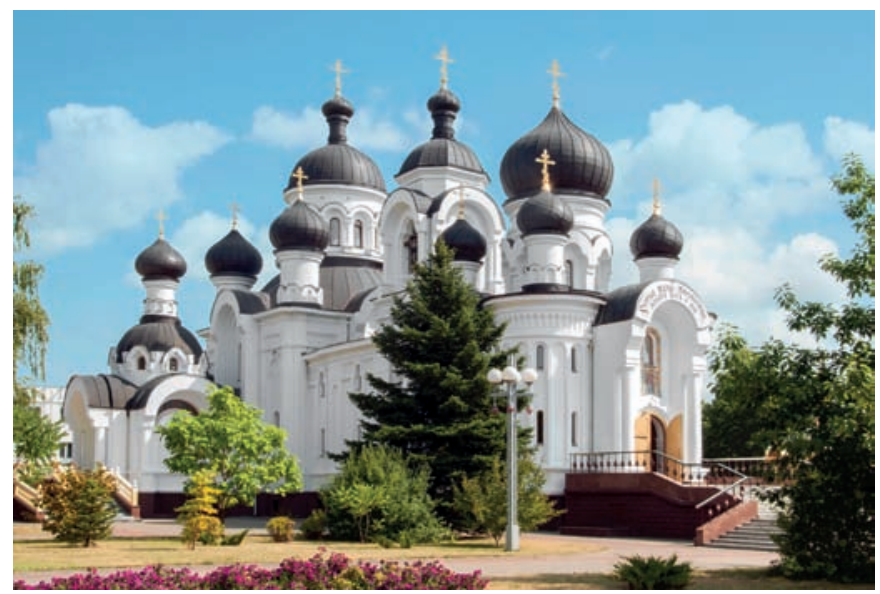

Рис. 2. Храм св. Жен-мироносиц. Барановичи, Беларусь. Архитектор. Л. Макаревич. 2007 год. Фото И.И. Балуненко века; 2) интерпретация традиций белорусского сакрального зодчества.

В условиях прерванной церковной преемственности «возрождение» традиции в 1990-е годы привело к формированию новых культурных практик, имитировавших происхождение от обычаев древности - то есть происходило «изобретение традиции», в терминологии историка Э. Хобсбаума [2, с. 1]. Основой изобретённых традиций стали мгновенно распознаваемые символы Православия [3, с. 15]: троеперстное крестное знамение, восьмиконечный крест, крестово-купольный храм с золотыми куполами. Аутентичные готические, ренессансные, барочные православные храмы, сохранившиеся на территории современной Беларуси, воспринимаются как неканоничные [3, с. 12]. Преобладает стилизация работ архитектурных школ, исторически не существовавших на территории современной Беларуси, либо повторение образцов «русского стиля», вытеснившего локальные традиции храмового зодчества во второй половине XIX века [3, с. 12; 4, с. 84]. В храмостроительство Беларуси проникают исторически чуждые элементы: пятиглавие, луковичные главы, шатровые крыши, многоярусные декоративные кокошники, ложные закомары.

Среди возведённых в 1990-е - 2010-е годы храмов можно отметить стилизации владимиро-суздальской, псковско-новгородской, московско-ярославской школ (храм Св. Евфросинии Полоцкой, 1996, Минск, арх. Н. Дятко, рис. 1; храм-памятник во имя Всех святых, 2008, Минск, арх. Л. Погорелов); русско-византийского и «русского» стилей (храм иконы Божьей Матери «Всех Скорбящих Радости», 1998, арх. Н. Дятко; храм Жён Мироносиц, 2007, Барановичи, арх. Л. Макаревич, рис. 2). Деревянные церкви 1990-х - 2000-х годов повторяют облик шатровых храмов Русского Севера с горизонтальной облицовкой и характерным трёхчастным членением объёма на притвор с колокольней, трапезную и наос (храм в честь прп. Оптинских старцев, 2013, ул. Космонавтов, Минск, арх. Т. Судиловская; храм св. Пантелеймона, 2006, мрн. Уручье, Минск).

Поиск национального своеобразия в современной православной архитектуре Беларуси проявляется в использовании выразительных приёмов православной и греко-католической архитектуры, сложившихся в культуре белорусско-польского пограничья [5, с. 98]. Колокольни церкви иконы Минской Божьей Матери в Минске (2001, арх. А. Трухин) повторяют фланкирующие башни православных готических храмов оборонного типа (XV-XVI века). Облик церкви Всех Святых в Гродно (2011, арх. Н. Емельянова) выполнен в традициях гродненской школы зодчества середины XII века. В интерпретации местных особенностей православного Ренессанса, барокко и классицизма прослеживается художественный компромисс с архитектурой «русского» стиля (Богоявленская церковь, 1998, Глуск, арх. В. Балейко; храм св. Троицы, 1996, д. Достоево, Брестская обл., арх. В. Кулин; храм св. Троицы, 2000, Мядель, арх. Н. Лукьянчик). 
Свойственное белорусской архитектуре XVIII-XIX веков проникновение приёмов архитектуры барокко и классицизма в деревянное народное зодчество прослеживается в храме св. Николая Чудотворца (1999, мрн. Шабаны, Минск, арх. Т. Судиловская), храме Иоанна Предтечи (2008, д. Дудутки, Минская обл., арх. Н. Лукьянчик). Облик храма св. Николая Чудотворца (1988-1990, д. Мороськи, Минская обл.) повторяет национал-романтические черты церкви св. Николая Чудотворца в деревне Верховичи (1933, Брестская обл.). Двухъярусная двускатная крыша храма Покрова Пресвятой Богородицы (1774, д. Гончары, Гродненская обл.) воспроизведена в храме св. Елисея Лавришевского (1997, д. Минойты, Гродненская обл.).

Экспериментальное православное храмостроительство развивается в рамках постмодернистского направления, общего для Беларуси, западной и центральной Украины и восточной Польши 1990-х - середины 2010-х годов. Простота соединения «традиционных» и современных элементов в облике постмодернистского храма обусловила возникновение тенденции, которая в каждом из регионов проявляется в собственных формах: деконструкция крестово-купольной композиции церквей восточной Польши [6, с. 37], переосмысление барочного и неоклассического декора в Украине [7, с. 358-360]. Белорусское направление характеризует лаконизм и сочетание приёмов постмодернизма и неомодернизма, интерпретация не местных особенностей, а заимствованного образа крестово-купольного храма с белыми стенами (собор Воскресения Христова, 2008, Минск, арх. В. Романенко; проекты арх. В. Даниленко: храм св. Евфросинии Полоцкой, 1998, Ивенец; Рождества Пресвятой Богородицы, 2000, Солигорск; Богородицы Избавительницы, 1993, Жодино). Купола, арочные своды и полуциркульные завершения проемов преобразуются в парусообразные конструкции, криволинейные оболочки, подковообразные проёмы, каскады полусферических выступов [7, с. 357].

Католическая архитектура Беларуси в контексте Второго Ватиканского Собора (1962-1964, Рим, Италия). Эксперименты в католическом зодчестве рубежа XX-XXI веков обусловлены постановлениями принятой на Соборе «Конституции о святой литургии». В главе «Священное искусство и священные предметы культа» постулируются открытость Католической церкви к новаторским художественным тенденциям и современным архитектурным стилям, стремление к лаконичному выразительному решению с ограниченным использованием декора и священных изображений [8]. Тем не менее в католической архитектуре Беларуси, как и в православной, приоритетно проявление связи с традициями храмового зодчества. Строительство костёлов ведётся в двух направлениях: 1) эклектичном переосмыслении локальных особенностей сакральной архитектуры XIV-XVIII веков; 2) авангардном, которое порывает со сформировавшимися в белорусском католицизме художественными конвенциями. Основным признаком, характеризующим облик костёла как тяготеющего к историзму или авангарду, является симметрия либо асимметрия композиции [1, с. 51]. В местной традиции католической архитектуры была распространена продольноосевая симметрия однонефного костела-базилики. Смещение объёмов, асимметричная композиция появляются только как веяние архитектуры второй половины XX века.

Историзм и эклектика в современной католической архитектуре основана в первую очередь на традиционной для западного христианства семантике Ковчега Спасения: продольной прямоугольной в плане базилики, в которой параллельные нефы разделены рядами столбов или колонн [1, с. 51]. Архитектурно-художественный образ в духе историзма основан не на прямых отсылках к архитектуре ВКЛ и Речи Посполитой, но к её интерпретации в оптике эклектизма второй половины XIX века: неоготики, неороманики, необарокко (костёлы: Святой Троицы, 1993, Докшицы, рис. 3; Божьей Матери, 1997, Мосты, архитекторы А. Штен, И. Козловский и др.; св. Казимира, 1999, Логойск, архитектор Н. Колечиц, рис. 4; св. Иосифа, 2016, Брест, архитектор А. Андреюк, рис. 5). Так как использование декора ограничено идеями Второго

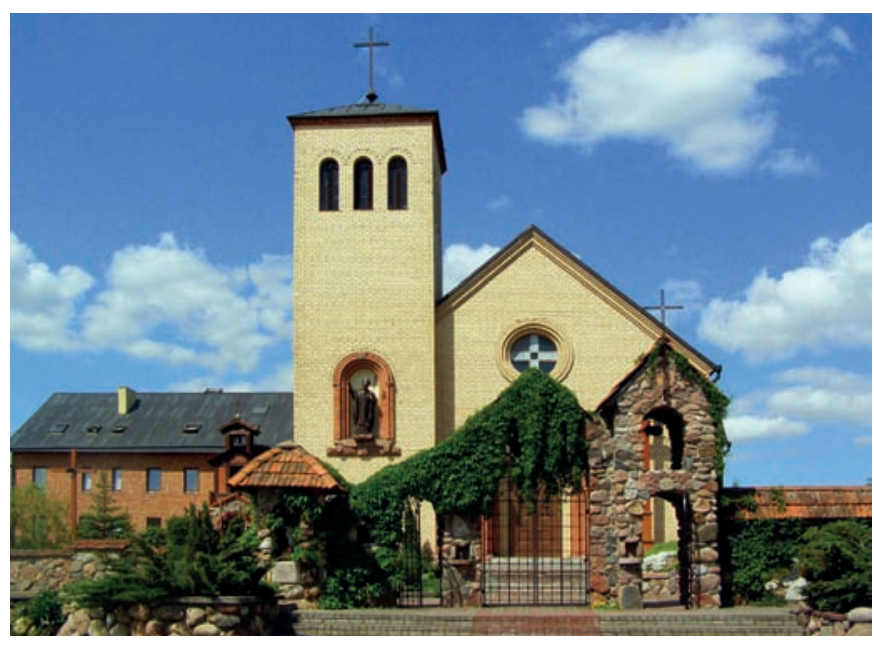

Рис. 3. Костёл Святой Троицы. Докшицы, Беларусь. 1993 год. Фото В. Садовского

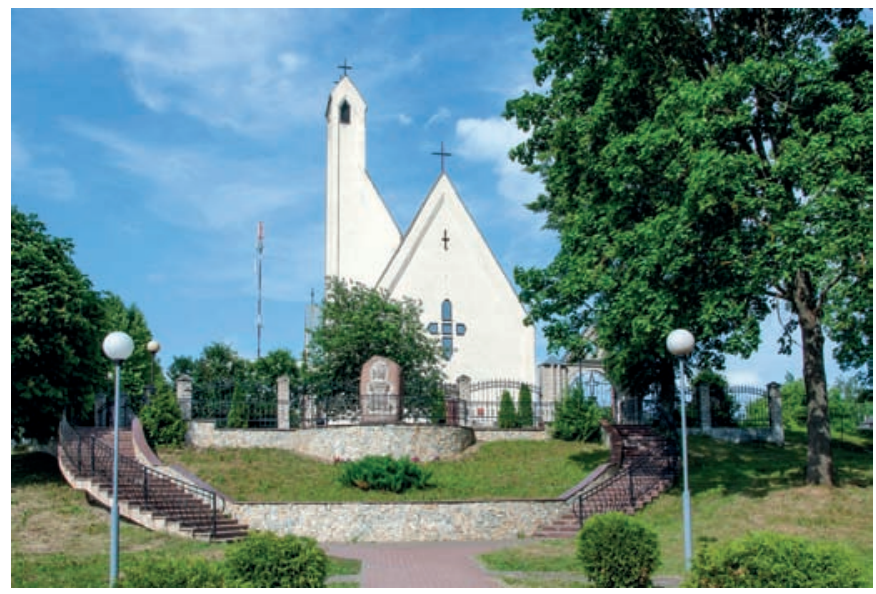

Рис. 4. Костёл св. Казимира. Логойск, Беларусь. Архитектор Н. Колечиц. 1999 год. Фото В. Садовского 
Ватиканского Собора, эклектизм проявляется в объёмнопространственном решении, силуэте здания. Выразительным акцентом выступает двускатная крыша, подчеркивающая продольную композицию «корабля» и создающая впечатление заостренности, вертикальной направленности пропорций, которая придает зданию «неоготическую» образность. Историзм нельзя рассматривать как исключительно локальное явление, так как лаконичное неомодернистское прочтение композиции однонефной базилики с двускатной крышей распространено в католическом зодчестве Западной Европы рубежа XX-XXI веков.

Авангардное направление в католической архитектуре Беларуси. Современные костёлы с постмодернисткими, деконструктивистскими и неомодернистскими чертами возводят преимущественно в западных регионах Беларуси. Композиция, форма оконных проёмов и отделка новаторских католических храмов гродненской и брестской областей сходны с аналогичными решениями в архитектуре Польши последней трети XX века, что свидетельствует о культурном обмене между регионами. На динамичных диагоналях и вертикалях строится композиция костёлов Милосердия Божьего (2002, мрн. Вишневец, Гродно, арх. А. Штен, 3. Казакевич), Непорочного Зачатия Девы Марии (кон. 1990-х, пос. Южный, Гродно, арх. А.

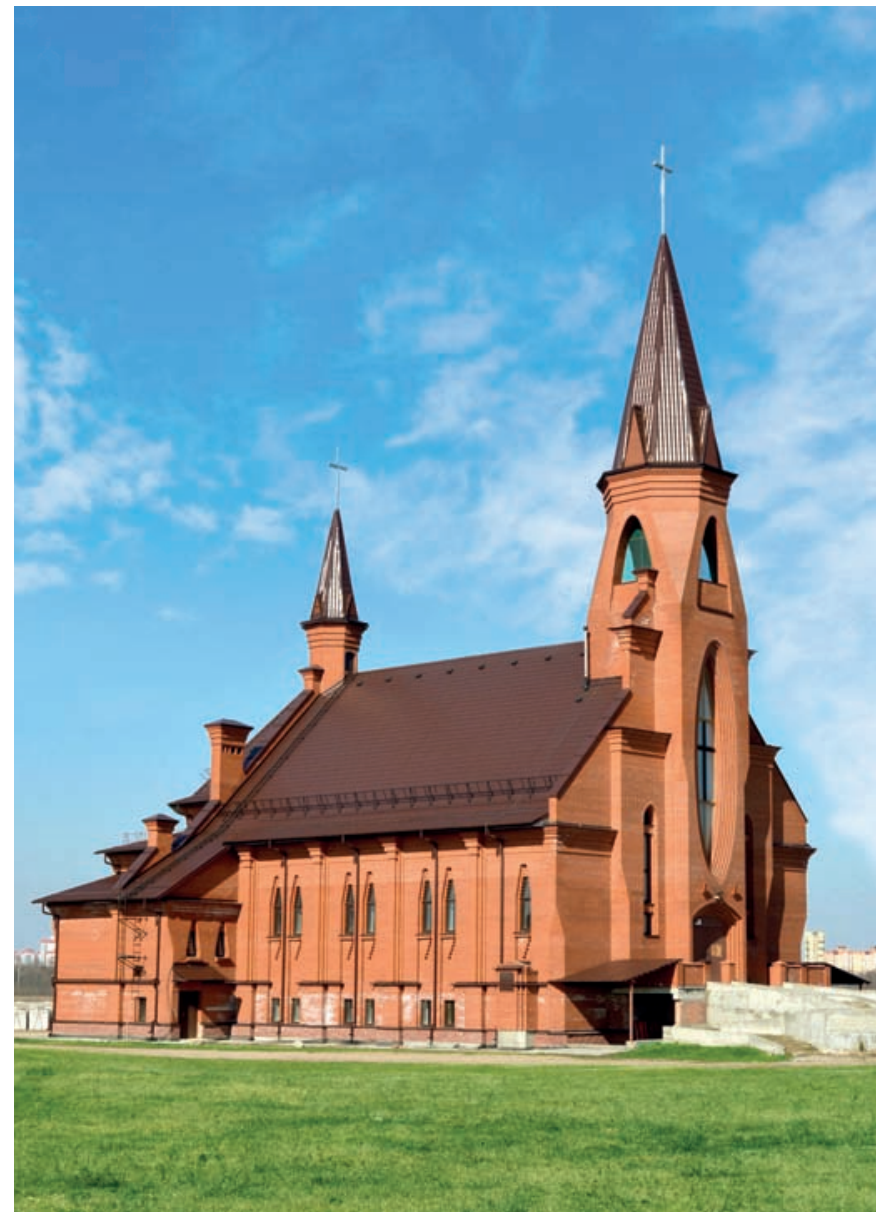

Рис. 5. Костёл св. Иосифа. Брест, Беларусь. Архитектор А. Андреюк. 2016 год. Фото В. Садовского
Тараненко), Вознесения Девы Марии (2000-е, мрн. Индустриальный, Лида). В строгих линиях комплекса католического центра Пресвятого Искупителя (2000-е, Гродно, арх. А. Штен, И. Козловский, Т. Черная) прослеживается влияние неомодернизма. Постмодернистское прочтение неоготики лежит в основе образного решения костёлов Иоанна Крестителя (2004, аг. Волма, Дзержинский р-н, арх. А. Базевич), Божьей Матери Фатимской (2003, Жодино, арх. И. Кныш). Объёмнопространственная композиция костёла Божьего Милосердия (2000-е, мрн. Молодежный, Лида) с необарочным фасадом деформирована асимметричными разномасштабными пристройками и башнями разной высоты и формы.

Современные протестантские храмы: региональные особенности и культурные заимствования. Строительство протестантских храмов, которые отличаются строгостью архитектуры, неприятием роскоши в убранстве, простотой выразительных средств, велось на территории Великого Княжества Литовского с середины XVI века до середины XVII века. B XVII веке дома молитвы были перестроены в костёлы, а в XIX веке преобразованы в православные церкви, во многом утратив аутентичные черты: готико-ренессансный облик, от-

${ }^{1}$ Разрешение на использование у автора фото получено.

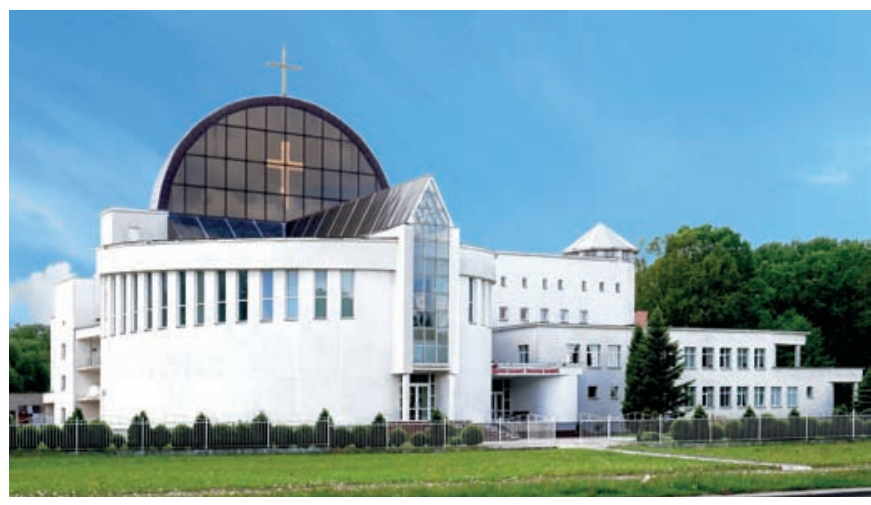

Рис. 6. Дом молитвы христиан-евангелистов «Вифлеем». Минск. Архитекторы Б. Школьников, Л. Сазонова, Е. Урбан. 2002 год. Фото И.И. Балуненко

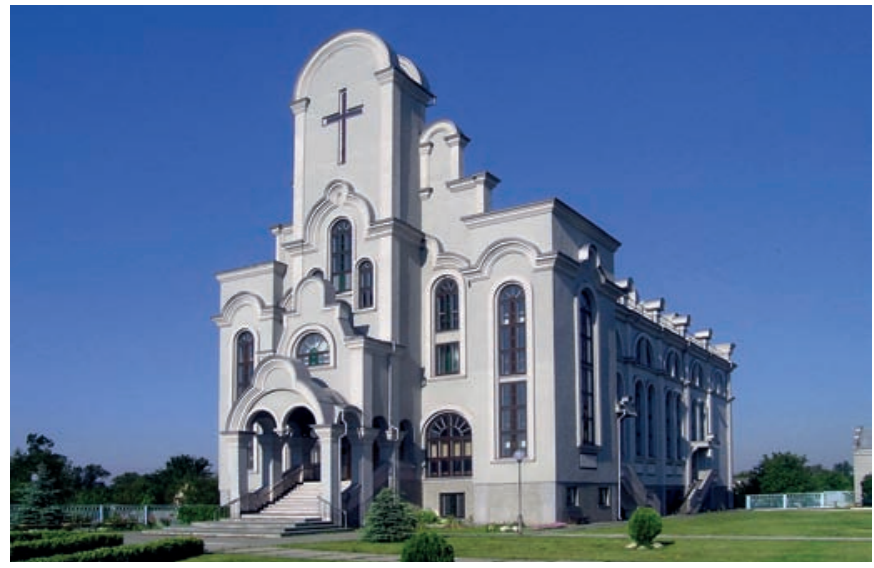

Рис. 7. Дом молитвы христиан-евангелистов. Кобрин, Беларусь. Архитектор А. Андреюк. 1994 год. Фото Н.Г. Лаврецкого ${ }^{1}$ 
сутствие алтарной апсиды и т.д. Всплеск строительства протестантских домов молитвы в Беларуси в 1990-е - 2000-е годы обусловлен ростом общин евангельских христиан-баптистов. Исторический перерыв в протестантском храмостроительстве был значительно больше, чем в католицизме и православии, поэтому архитекторы белорусских домов молитвы реже обращаются к историческим прообразам в своей работе. В Беларуси преобладают два подхода к формообразованию протестантских храмов: 1) постмодернизм в духе протестантской архитектуры США последней трети XX века; 2) историзм с ориентацией на выразительные средства православного и католического зодчества и ренессансные приемы протестантской архитектуры XVI века.

Постмодернизм и неомедернизм в облике дома молитвы развивается под влиянием протестантской архитектуры США 1970-х - 1990-х годов, так как возрождение протестантизма в Беларуси во многом связано с миссионерской деятельностью американских проповедников. В храмах евангельских христиан-баптистов более явно, чем у католиков и православных, выражены минималистичные тенденции (церковь «Благодать», 1996, Минск, арх. В. Никитин; церковь «Надежда», 2000-е, Гродно, арх. А. Штен, Т. Черная, С. Мужейко; Новоапостольская церковь, 2000, Минск, арх. М. Рыбников, Ю. Комиссаров и др.), которые в отдельных случаях приближаются к стилистике неомодернизма [10, с. 334] (церковь «Вифлеем», 2002, Минск, арх. Б. Школьников, Л. Сазонова, Е. Урбан, рис. 6). Широкое использование сплошного остекления и световых фонарей позволяет архитекторам создавать экспрессивные, залитые светом интерьеры.

Влияние деконструктивизма прослеживается в сложной разновысотной композиции церкви «Спасение» (2004, дер. Колодищи, Минский р-н арх. А. Андреюк, М. Давыдовский): обтекаемая эллиптическая в плане форма молитвенного зала противопоставлена острым, почти готическим формам фронтонов главного фасада.

Историческая стилизация в архитектуре молитвенных домов. Проникновение идей «возрождения традиции»из католической и православной в протестантскую архитектуру объясняет приемы барокко, готики и русского православного зодчества в облике дома молитвы христиан-евангелистов в Кобрине (1994, арх. А. Андреюк, рис. 7) и в Каменце (2001, apx. А. Андреюк). В протестантских молитвенных домах применяются остроугольные неоготические формы современных костелов (церковь «Божьей Милости», нач. 2000-х, Заславль) и характерные для православных храмов полуциркульные арочные проемы и скругленные очертания.

Авторы проекта церкви евангельских христиан-баптистов в городе Мосты (2000-е, арх. А. Штен, Т. Черная, С. Мужейко) вдохновились традициями архитектуры местных деревянных мечетей. Дом молитвы представляет собой куб, перекрытый четырехскатной крышей, по центру увенчанной световым фонарем со шпилем. Главный фасад оформлен неоклассическим двухъярусным многоколонным портиком.
***

Сакральная архитектура является одним из визуальных якорей, скрепляющих белорусскую культуру рубежа XX-XXI веков и проявляющих ее поликонфессиональный характер. В культовых зданиях и сооружениях отражается региональная самобытность Беларуси и культурное влияние Западной Европы, США, России, Украины и Польши. Главенствует тенденция, направленная на переосмысление традиций храмового зодчества; новаторские выразительные средства проникают в храмовую архитектуру преимущественно в рамках постмодернизма, который опирается в основном на принципы эклектичного историзма и традиционной сакральной семантики.

\section{Лuтература}

1. Габрусь, Т.В. Композиционные принципы современного сакрального зодчества Беларуси: традиции и инновации / Т.В. Габрусь // Традыцыі і сучасны стан культуры і мастацтваў / Матэрыялы Міжнароднай навукова-практычнай канферэнцыі (10-11 лістапада 2011 г, г. Мінск) - Мінск : Права і эканоміка, 2011. - C. 48-54.

2. The Invention of Tradition / E. Hobsbawm, T. Ranger (eds.). - Cambridge : Cambridge Univ. Press, 1984. - VI, 320 p.

3. Балуненко, И.И. Возможна ли реформа православного храмостроительства? / И.И. Балуненко // Збожжа : [зб. нав. арт.] / Цэнтр «Экумена»; гал. рэд. Н. Васілевіч. - Мінск, 2019. - Вып. 1. - С. 7-23.

4. Вараб'ёў, В. Пошукі архітэктурна-мастацкага вобраза сучаснага праваслаўнага храма Беларусі / В. Вараб'ёў // Архитектура и строительство. - 2009. - № 1/2. - С. 82-87.

5. Устинович, Е. Новые церкви в Белостоке и Гродно: традиции архитектуры пограничья / Е. Устинович // Архитектура и стр-во. - 2010. - № 3. - С. 98-101.

6. Устинович, Е. Между Востоком и Западом: культовая архитектура Польши второй половины XX века / Е. Устинович // Архитектура и стр-во. - 2007. - № 9. - С. 36-40 - № 10. - С. 38-41.

7. Балуненко, И.И. Постмодернизм в православной храмовой архитектуре конца XX - начала XXI века: опыт Беларуси, Украины, России и Польши / И.И. Балуненко // Історія релігій в Україні: науковий збірник світлій пам'яті професора Ярослава Дашкевича (1926-2010) / за заг. ред. М. Капраля, 0. Киричук, І. Орлевич. - Львів: Інститут релігієзнавства філія Львівського музею історії релігії, «Логос», 2016. - Частина 3: Сакральні пам'ятки. - С. 354-366.

8. Constitution of the Sacred Liturgy, Sacrisanctum Concilium [Electronic resource] : solemnly promulgated by His Holiness Pope Paul VI on Dec. 4, 1963 // The Holy See : the offic. Vatican webpage. - Mode of access: http://www.vatican. va/archive/hist_councils/ii_vatican_council/documents/ vat-ii_const_19631204_sacrosanctum-concilium_en.html\#top - Date of access: 28.03.2021.

9. Каталіцкія святыні: Мінска-Магілёўская архідыяцэзія / Тэкст і фота А. Яроменкі. - Частка 1. - Мінск : Про Хрысто, 2003. - C. 114-118. 
10. Шамрук, А.С. Строительство католических и протестантских храмов / А.С. Шамрук // Современная Беларусь: Энциклопедический справочник в трех томах. - Т.3. - Культура и искусство. - Минск : Беларуская навука, 2007. - С. 333-337.

\section{References}

1. Habrus T.V. Kompozitsyonnie printsipy sovremennogo sacralnogo zodchestva Belarusi: traditsii i innovatsii [Compositional principles of modern sacred architecture of Belarus: traditions and innovations]. In: Materialy Mezhdunarodnoi nauchno-prakticheskoi konferentsii "Traditsii i sovremennoe sostoyanie kul'tury i iskusstva", 10-11 noyabrya $2011 \mathrm{~g} ., \mathrm{g}$. Minsk) [Proceedings of the International Scientific and Practical Conference "Traditions and the current state of culture and arts", November 10-11, 2011, Minsk]. Minsk, Law and Economics Publ., pp. 48-54.

2. Hobsbawm E., Ranger T. (eds.) The Invention of Tradition. Cambridge, Cambridge Univ. Press, 1984, VI, 320 p.

3. Balunenka I.I. Vozmozhna li reforma pravoslavnogo hramostroitel'stva? [Is the reform of Orthodox church building possible?] In: Sbornik nauchnykh statei "Zbozhzha" [Collection of science articles "Zbozhzha"], N. Vasilevich (ch.ed.). Minsk, 2019, Iss. 1, pp. 7-23.

4. Varab'ey V. Poshuki arkhitekturna-mastatskaga vobraza suchasnaga pravaslay̆naga khrama Belarusi [Search for the architectural and artistic image of the modern Orthodox Church of Belarus]. In: Arkhitektura i stroitel'stvo [Architecture and Construction], 2009, no. 1-2, pp. 82-87.

5. Ustinovich E. Novye tserkvi v Belostoke i Grodno: traditsii arkhitektury pogranich'ya [New churches in Bialystok and Grodno: traditions of borderland architecture]. In: Arkhitektura i stroitel'stvo [Architecture and Construction],2010, no. 3, pp. 98-101.
6. Ustinovich E. Mezhdu Vostokom i Zapadom: kul'tovaya arkhitektura Pol'shi vtoroi poloviny XX veka [Between East and West: the cult architecture of Poland in the second half of the $X X$ century]. In: Arkhitektura i stroitel'stvo [Architecture and Construction], 2009, no. 9, pp. 36-40\$ no. 10, pp. 38-41.

7. Balunenka I.I. Postmodernizm v pravoslavnoi khramovoi arkhitekture kontsa XX - nachala XXI veka: opyt Belarusi, Ukrainy, Rossii i Pol'shi [Postmodernism in Orthodox temple architecture of thelate XX - early XXI century: the experience of Belarus, Ukraine, Russia and Poland]. In: M. Karpalya, 0. Kirichuk, I. Orlevich (eds.) "Istoriya religii v Ukraïni: naukovii zbirnik svitlii pam'yati profesora Yaroslava Dashkevicha (1926-2010)" [History of religions in Ukraine: scientific collection of the blessed memory of Professor Yaroslav Dashkevich (1926-2010)]. Lviv, Institute of Religious Studies, a branch of the Lviv Museum of the History of Religion, Logos, 2016, Part 3: Sacred monuments, pp. 354-366.

8. Constitution of the Sacred Liturgy, Sacrisanctum Concilium, solemnly promulgated by His Holiness Pope Paul VI on Dec. 4, 1963. The Holy See. Vatican webpage. Access mode: http://www.vatican.va/archive/hist_councils/ii_vatican_ council/documents/vat-ii_const_19631204_sacrosanctumconcilium_en.html\#top (Accessed 03/28/2021).

9. Jaromenki A. Katalickija svjatyni: Minska-Magiljowskaja arhidyjacjezija [Catholic shrines: Minsk-Mogilev archdiocese], Part 1. Minsk, About Christ Publ., 2003, pp. 114-118.

10. Shamruk A.S. Stroitel'stvo katolicheskih i protestantskih hramov [Construction of Catholic and Protestant churches]. In: Sovremennaja Belarus': Jenciklopedicheskij spravochnikv treh tomah, T.3. Kul'tura i iskusstvo [Modern Belarus: Encyclopedic reference book in three volumes. Vol.3. Culture and art]. Minsk, Belarusian Science Pb., 2007, pp. 333-337.

Габрусь Тамара Викторовна (Минск, Беларусь). Доктор искусствоведения, доцент. Ведущий научный сотрудник отдела архитектуры ГНУ «Центр исследований белорусской культуры, языка и литературы НАН Беларуси» (220072, Беларусь, Минск, ул. Сурганова, 1, корп. 2). Эл.почта: gabrustv@mail.ru.

Балуненко Ирина Ивановна (Минск, Беларусь). Кандидат искусствоведения, доцент. Старший научный сотрудник отдела архитектуры ГНУ «Центр исследований белорусской культуры, языка и литературы НАН Беларуси» (220072, Беларусь, Минск, ул. Сурганова, 1, корп. 2). Эл.почта: iryna.balunenka@gmail.com.

Gabrus Tamara V. (Minsk, Belarus). Doctor of Art History, Associate Professor. Leading Researcher at the Department of Architecture of the Center for the Belarusian Culture, Language and Literature Researches of the National Academy of Sciences (1 Surhanava St, building 2, Minsk, Republic of Belarus, 220072. The Center for the Belarusian Culture, Language and Literature Researches of NASB).E-mail: gabrustv@mail.ru.

Balunenko Iryna I. (Minsk, Belarus). Candidate of Art History, Associate Professor. Senior Researcher at the Department of Architecture of the Center for the Belarusian Culture, Language and Literature Researches of the National Academy of Sciences (1 Surhanava St, building 2, Minsk, Republic of Belarus, 220072. The Center for the Belarusian Culture, Language and Literature Researches of NASB). E-mail: iryna.balunenka@gmail.com. 